\title{
Clinical and etiological aspects of ptosis at university hospital of cotonou
}

\author{
Alamou $\mathrm{S}^{1 *}$, Assavedo $\mathrm{Cra}^{2}$, Abouki COA${ }^{1}$, Godonou $\mathrm{Nye}^{1}$, Sounouvou $\mathrm{I}^{1}$, Yehouessi $\mathrm{L}^{1}$, Tchabi $\mathrm{S}^{1}$ and Doutetien $\mathrm{C}^{1}$ \\ ${ }^{1}$ Department of Ophthalmology, HKM University Hospital of Cotonou, Benin \\ ${ }^{2}$ Ophthalmology Unit, Faculty of Medicine,University of Parakou, Benin
}

\begin{abstract}
Ptosis is a rare disease in ophthalmic consultation. It results in the abnormal drooping of the upper eyelid muscle by weakness of the upper eyelid or its innervation. The aim of this work is to study the clinical and ethological aspects of ptosis in the University Hospital "Hubert Koutoukou Maga" of Cotonou (CNHU-HKM). It was a 10-year retrospective and descriptive study which covered from $1^{\text {st }}$ January 2004 to 31 December 2013. Among the 45,924 patients examined, 58 showed ptosis (frequency $0.13 \%$ ). Patients are ranged from 1 to 69 years old with a mean age of 28.7 years. The sex ratio was 2.2 with men. $94.8 \%$ were referred by a doctor. Visual impairment (34.5\%) and eyelid swelling (25.9\%) were dominant. 73 eyes were affected by ptosis among which 43 (73.1\%) unilateral. The symptoms onset and the first consultation was 7 days in $60.3 \%$ of cases. The settlement method was progressive in $56.9 \%$. Ptosis was acquired in $76.7 \%$ of cases. Traumatic causes topped the list (42.9\%) followed by myogenic (21.4\%) and neurogenic (10.7\%).
\end{abstract}

\section{Introduction}

Ptosis is when the upper eyelid droops over the eye. it may droop just a little or so much that it covers the pupil. It is a rare disease encountered in ophthalmological consultation in Benin's hospitals. It is an inefficiency of the upper eyelid muscle either by myogenic, neurogenic or disintegration of the aponeurosis or by abnormal innervation of the concerned muscle [1]. It can be unilateral or bilateral. This has as a consequence, in addition to the functional aesthetic defect, the risk of the appearance of an amblyopia in the child especially when it is congenital. The literature on its prevalence is mainly of Western origin because very few isolated studies exit on the epidemiology of psotis. The aim of the present study is to determine the epidemiological profile of ptosis, to describe the clinical aspects and to identify the main etiologies in the University Hospital of Cotonou.

\section{Method}

It is a-10 year, retrospective and descriptive study that covered from $1^{\text {st }}$ January 2004 to 31 December 2013. The study population consisted of patients of both sexes suffering from ptosis who consulted during the period in the Ophthalmology Clinic in the University Hospital of Cotonou. Here we used socio-demographic variables such as age, sex, occupation, educational level, added to clinical and etiological one. Ptosis disease is said to be:

- minor, when the difference in level between the two free edges is less than or equal to $2 \mathrm{~mm}$.

- moderate when the difference is between 2 and $4 \mathrm{~mm}$.

- major, when the difference is greater than $4 \mathrm{~mm}$ [1].

Data processing was made using Microsoft Office Excel 2013 software.

Analysis and processing of the data was made using SPSS 21 software. The degree of significance is $p \geq 0.05$.

\section{Results}

Epidemiological aspects.

Frequency.

Among the 45924 patients received during the study period, 58 ptosis cases were recorded, that means a frequency of $0.13 \%$.

Age

Patients were aged from 1 to 69 years with a mean age of $28.7 \pm 19.8$ years. The age group under 15 years of age was the most affected, with $31.1 \%$ of cases. Then, those between $16-30$ years and 31-45 years with $24.1 \%$ of cases each as illustrated in Table 1 .

\section{Sex}

Ptosis was higher in men (69\%) than in women (31\%). The sex ratio was 2.2.

\section{Method of admission}

Very few patients were referred by a doctor. The majority consulted on their own initiative in $94.8 \%$.

Clinical aspects

Complaints

Those recorded in patients were recorded in Figure 1.

Correspondence to: Alamou soulé, Department of Ophthalmology, HKM University Hospital of Cotonou, 04Box 0848 Cotonou, Benin, Tel: 002299713 69 86; E-mail: s_alamou@yahoo.fr

Key words: congenital ptosis, acquired, traumatic, myogenic, neurogenic, upper eyelid

Received: May 20, 2017; Accepted: June 16, 2017; Published: June 19, 2017 


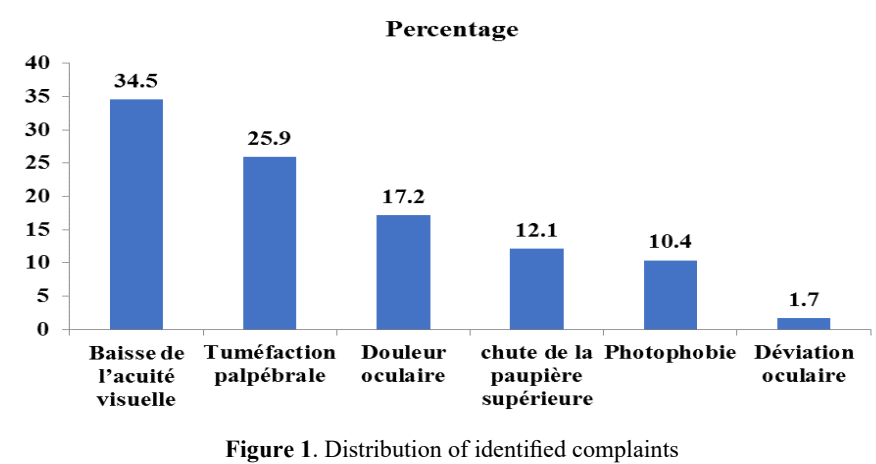

The decrease in visual acuity $(34.5 \%)$ and palpebral tumefaction $(25.9 \%)$ were more accurate. The upper eyelid droop was recorded in $12.1 \%$ of cases.

Table 1. Distribution of patient by Age

\begin{tabular}{|c|c|c|}
\hline & Number & \% \\
\hline$<15$ year & 18 & 31,1 \\
\hline $16-30$ years & 14 & 24,1 \\
\hline $31-45$ years & 14 & 24,1 \\
\hline $46-60$ years & 8 & 13,8 \\
\hline$>60$ years & 4 & 6,9 \\
\hline Total & $\mathbf{5 8}$ & $\mathbf{1 0 0}$ \\
\hline
\end{tabular}

\section{Laterality}

The impairment was predominantly unilateral $(74.1 \%)$ as shown in Table 2 . The left eye was the most affected in $41.4 \%$ of cases.

\section{At the beginning}

The beginning of ptosis was progressive in more than half of the patients $(56.9 \%)$. The consultation period was between 1 day and 20 years with a median of 7 days.

Visual acuity

The distribution related to visual acuity is illustrated in Table 3 .

\section{Degree of ptosis}

The distribution according to the degree of the palpebral fall is noted in Table 4.

Ptosis was major in $23.3 \%$ of cases.

The acquired ptosis was $76.7 \%$ (56 eyes). The causes of the acquired ptosis are shown in the Table 5.

\section{Discussion}

\section{Socio-demographically}

Ptosis is one of the rare diseases recorded in Ophthalmological consultation in the University Hospital of Cotonou (0.13\%). This low occurrence was observed by Hashemi et al. who obtained $0.90 \%$ of cases of ptosis in ophthalmic diseases [2] in Iran in 2010. On the other hand, Baggio and Ruban [3] recorded in Europe in 2002, 884 cases of ptosis among 1450 consultants for palpebral affections, or $60 \%$ of the palpebral affections.

The low frequency observed in our study could be explained by the ignorance of patients who rarely consult for eyelid drooping, or by traditional belief which makes certain pathologies of children at birth constitute a taboo or are considered as a mystic spell.

The male predominance observed in the present study (69\%) was observed by Rivière et al. [4] in 2007 in France with $59 \%$ and by
Hashemi et al. [2] in Iran in 2010. This can be explained by a high exposure of men to traumatic related accidents resulting in ptosis.

The majority of patients (94.8\%) who consulted on their own initiative in University Hospital of Cotonou, is explained by the fact that it is the referral hospital in Cotonou.

\section{Clinical presentation}

The main identified annoyances ranged from decreased visual acuity to palpebral tumefaction in $34.5 \%$ and $29.4 \%$, respectively. This palpebral tumefaction is often post traumatic. For Handor et al. [5] in Morocco in 2014, aesthetic discomfort was the most reported in $65.9 \%$ of cases.

The ptosis is often unilateral, like in our study, Riviere et al. [4] recorded a rate of $74 \%$ unilateral attacks. Higher rates were reported by Handor et al. [5] and Hashemi et al. [2] respectively $90.9 \%$ and $95 \%$. The left eye was the most affected in our series because a punch is usually blown with the right hand.

Only $39.7 \%$ of patients consulted a doctor within seven days of the eyelid drooping onset. More than a year and six months passed before the majority of patients consulted. This delay in consultation could be explained by the non-painful nature of non-traumatic ptosis, the absence of any real visual discomfort in the light ptosis. Amblyopia was noted in $20.5 \%$ of cases, more than $14.9 \%$ with Gregory et al. [6] in

Table 2. Distribution of patients according to the laterality of the ptosis

\begin{tabular}{|c|c|c|}
\hline & Number & $\mathbf{\%}$ \\
\hline Right Unilateral & 19 & 32,7 \\
\hline Left Unilateral & 24 & 41,4 \\
\hline Bilateral & 15 & 25,9 \\
\hline Total & $\mathbf{5 8}$ & $\mathbf{1 0 0}$ \\
\hline
\end{tabular}

For the 58 patients mentioned above, we have 15 bilateral cases ( 30 ptosis), 43 unilatera cases which constitutes a total of 73 ptosis.

Table 3. Distribution related to visual acuity

\begin{tabular}{|c|c|c|}
\hline & Number & $\mathbf{\%}$ \\
\hline$<3 / 10$ & 15 & 20,5 \\
\hline $3 / 10 \leq \mathrm{AV}<7 / 10$ & 34 & 46,6 \\
\hline$\geq 7 / 10$ & 24 & 32,9 \\
\hline Total & $\mathbf{7 3}$ & $\mathbf{1 0 0}$ \\
\hline
\end{tabular}

$67.1 \%$ of eyes had a decrease in visual acuity.

Table 4. Distribution related to the degree of ptosis

\begin{tabular}{|c|c|c|}
\hline & Number & $\mathbf{\%}$ \\
\hline Minor & 31 & 42,5 \\
\hline Moderated & 24 & 32,9 \\
\hline Major & 17 & 23,3 \\
\hline NR & 01 & 1,3 \\
\hline Total & $\mathbf{7 3}$ & $\mathbf{1 0 0}$ \\
\hline
\end{tabular}

The upper palpebral fold was absent in $38.4 \%$ of cases. Corneal sensitivity was tested in only $16.4 \%$ of cases and was normal.

The congenital ptosis was 17 , for $23.3 \%$ of cases and all isolated.

Table 5. Distribution of eyes with acquired ptosis

\begin{tabular}{|c|c|c|}
\hline & Number & $\mathbf{\%}$ \\
\hline Neurogene & 6 & 10,7 \\
\hline Myogene & 12 & 21,4 \\
\hline Aponevrotic & 14 & 25 \\
\hline Traumatic & 24 & 42,9 \\
\hline Total & $\mathbf{5 6}$ & $\mathbf{1 0 0}$ \\
\hline
\end{tabular}

Trauma was the most observed cause of ptosis in $42.9 \%$ of cases. 
Wisconsin in 2013. Our results are, however, closer to that of Handor et al. (25\%) [5] in Morocco. This high percentage of the Moroccan study could be justified by the specificity of their series with congenital ptosis. Ptosis was minor in $42.5 \%$ of our series, which is significantly higher than that of Handor et al. (11.36\%) [5]. But the frequency of the minor form constitutes an advantage in the management of ptosis.

Ptosis was said major in $23.3 \%$ of our series, which was higher than the $18.18 \%$ of Handor et al. [5]. In all cases, this major ptosis requires early and adequate management to avoid amblyopia in congenital ptosis.

Our study revealed that the upper palpebral fold was absent in $38.4 \%$ of cases, which was contrary to the observations with some authors $[4,6]$ who found the palpebral bulge generally in good position. It should be noticed, however, that this information lacks in many of the patients in our series (30.1\%).

Corneal sensitivity was not reported in the majority of patients but was retained in all cases tested. The preservation of corneal sensitivity is a good prognostic factor in the management of this condition, which is essentially surgical. Indeed, a loss of corneal sensation implies an involvement of the Trijumeau nerve with risk of post-operative corneal lesion related to transient lagophthalmos, sometimes prolonged [1].

\section{Etiological presentation}

Congenital ptosis was evoked in $23.3 \%$ of cases. This proportion is much lower than that observed in the literature $[4,6]$, which notes the predominance of congenital ptosis in $75 \%$ of cases, probably due to parents' ignorance.

Congenital ptosis was isolated in our series, as highlighted by Handor et al. [5] who obtained a proportion of $91 \%$. However, they reported an association with blepharophimosis in $6.81 \%$ of cases and a syndrome of congenital fibrosis of the oculo-motor muscles in $2.27 \%$ of cases [5]. The acquired ptosis is often classified on the basis of its pathogenesis into five subgroups: myogenic, aponeurotic, neurogenic, mixed and false ptosis [7]. The majority of these ptosis are aponeurotic, usually associated with the disintegration or dehiscence of the aponeurosis of the levator muscle of the upper eyelid [8]. The $25 \%$ aponeurotic rate of ptosis in the current study is lower than that of $35.3 \%$ reported by Baggio et al. [7]. These were cases due to lack of technical equipment in developing countries.

\section{Conclusion}

Ptosis accounted for $0.13 \%$ of consultation causes in the clinic of ophthalmology in the University Hospital of Cotonou. It concerned predominantly male subjects and also young subjects with significant delay in consultation. The occurrence was generally one-sided. Patients often consulted for declined visual acuity and palpebral bulge. Ptosis was more often acquired and traumatic origin. This is mostly minor ptosis, usually with a palpebral fold of a preserved corneal sensitivity which presents a positive result when adequately managed.

\section{References}

1. Ruban JM, Baggio E (2009) Examen clinique d'un ptosis. Réfl Ophtalmol 14: 478-485.

2. Hashemi H, Khoob MK, Yekta AA, Mohammad K, Fatouhi A (2010) The prevalence of Eyelid ptosis in Tehyran, Iran Population: The Tehran Eye study. Iranian $J$ Ophthalmol 22: 3-6.

3. Baggio E, Ruban JM (2002) Affection palpébrale en Europe: bilan épidémiologique et statistique de 1450 case. Med Ophtalmol: 410-415.

4. Rivière M, Ferron A, Scholles F, Brugniart C (2007) Aspects épidémiologiques et prise en charge thérapeutique du ptosis. J Fr Ophtalmol 3: 25-48.

5. Handor H, Hafidi Z, Bencherif M, Amrani Y, Belmokhtar A (2014) Ptosis congenital: experience d'un centre de soins tertiaires marocain et de mise au point. PanAfr Med J $19: 150$.

6. Griepentrog GJ, Diehl N, Mohney BG (2013) Amblyopia in childhood eyelid ptosis. Am J Ophthalmol 155: 1125-1128. [Crossref]

7. Baggio E, Ruban JM, Boizard Y (2002) [Etiologic causes of ptosis about a serie of 484 cases. To a new classification?]. J Fr Ophtalmol 25: 1015-1020. [Crossref]

8. Griffin RY, Sarici A, Unal M (2006) Acquired ptosis secondary to vernal conjunctivitis in young adults. Ophthal Plast Reconstr Surg 22: 438-440. [Crossref]

Copyright: (C2017 Alamou S. This is an open-access article distributed under the terms of the Creative Commons Attribution License, which permits unrestricted use, distribution, and reproduction in any medium, provided the original author and source are credited. 